\title{
Os leitores de histórias em quadrinhos no meio das mentiras de
}

\section{Fredric Wertham ${ }^{1}$}

\section{Comic book readers at the center of Fredric Wertham's lies}

1. Conferência inaugural proferida nas 6as Jornadas Internacionais de Histórias em Quadrinhos, evento organizado pelo Observatório de Histórias em Quadrinhos da Escola de Comunicações e Artes da USP, em agosto de 2019, nas Escola de Comunicações e Artes da Universidade de São Paulo. Tradução de Érico de Assis.

2. Professora Associada da School of Information Sciences da University of Illinois, UrbanaChampaign, Estados Unidos.

Resumo: $\mathrm{O}$ legado de Fredric Wertham tanto como um psiquiatra como um combatente das histórias em quadrinhos é grandemente desconhecido for a dos Estados Unidos. As exceções são Canadá, Inglaterra, Austrália, Alemanha e Brasil. As ideias dele ganharam destaque no Brasil à medida em que o país lutava com seus próprios temores sobre a influência corruptora dos quadrinhos na vida dos jovens leitores. Depois de mencionar pesquisas anteriores sobre quadrinhos que focaram nos gatekeepers - bibliotecários, professores, pais e outros adultos -, que tentaram regular a leitura de quadrinhos dos jovens, o foco do artigo muda-se para os jovens em si. Proporciona-se um contexto sobre Fredric Wertham e os quadrinhos estadunidenses na metade do século 20 e então são discutidos alguns jovens específicos que Wertham estudou. Baseada nessas discussões, apresentam-se algumas observações conclusivas.

Palavras-chave: Censura nos quadrinhos. Fredric Wertham. Histórias em Quadrinhos Leitura.

Abstract: Fredric Wertham's legacy as either a psychiatrist or an anti-comics advocate is largely unknown outside of United States. The exceptions are Canada, England, Australia, Germany, and Brazil, His ideas gained currency in Brazil as the country struggled with its own fears about the corrupting influence of comics on the lives of child readers. After mentioning early scholarship on comics, focused on the gatekeeperslibrarians, teachers, parents, and other adults — who attempted to regulate young people's comics reading, the focus of the article is changed to young people themselves. A context about Fredric Wertham and US comics in the mid-20th century is provided and then the article discusses a few specific young readers who Wertham studied. Based on these remarks, some brief concluding remarks are offered.

Keywords: Comics censorship. Fredric Wertham. Comics reading. 


\section{Introdução}

Fora dos Estados Unidos, o legado de Fredric Wertham como psiquiatra e como cruzado antiquadrinhos é praticamente desconhecido. Há exceções, como no Canadá, na Inglaterra e na Austrália, onde o idioma em comum e a edição britânica de seu polêmico The seduction of the innocent (no Brasil, conhecido como $A$ sedução dos inocentes), de 1954, ajudou a impulsionar sua fama. Outra exceção é a Alemanha, terra natal de Wertham, onde suas ideias foram difundidas em palestras e artigos de uma de suas colegas mais próximas, a Dra. Hilde Mosse. E no Brasil, onde as ideias dele se disseminaram enquanto este país lidava com os próprios receios quanto à influência desvirtuadora dos gibis nas vidas dos leitores infantis.

Consequentemente, é uma grande honra estar aqui hoje para conversar um pouco sobre minha pesquisa a respeito de Fredric Wertham. Obrigado ao Professor Waldomiro Vergueiro e aos outros organizadores do evento pelo convite. Obrigado por me trazerem a São Paulo.

Os receios muito difundidos e transnacionais em relação ao hábito de ler quadrinhos, em meados do século 20, já foram caracterizados por vários acadêmicos como um pânico moral coletivo ou um pânico midiático coletivo. $\mathrm{O}$ historiador James Gilbert trata como uma impressão episódica, que ele define como uma ideia recorrente e aceita por muitos, "um quebracabeça cujo sentido não é aparente à primeira vista”, sendo que seus contornos podem aparecer de modo diferente dependendo de quem fala e de quem escuta (1988, p. 4).

Estes conceitos sócio-históricos servem de mapas: ferramentas úteis para entender o escopo de uma questão e como diferentes aspectos desta questão se interligam. $\mathrm{O}$ que estes conceitos não conseguem, tal como acontece com a maioria dos mapas, é dar uma perspectiva da experiência vivida de indivíduos. Por exemplo: boa parte do discurso sobre o pânico moral coletivo em torno dos quadrinhos serve como mapa para definir e descrever a trama de receios dos adultos quanto a esta mídia de massa, mas ao mesmo tempo renega as visões e perspectivas dos jovens a quem se dirigiam estas tensões sociais e culturais.

Minhas primeiras pesquisas sobre quadrinhos encaixavam-se aí. Eu era focada nos gatekeepers - bibliotecários, professores, pais e outros adultos - que tentaram regulamentar o que os jovens liam de quadrinhos. Graças em grande parte a Fredric Wertham, cada vez mais me convenço que vale mais centrar minhas pesquisas sobre quadrinhos nos próprios jovens.

Em fins de 2012 (TILLEY, 2012), eu publiquei um artigo - com base em vasta pesquisa documental - no qual eu apresentei algumas maneiras como Wertham inventou e fez má interpretação de partes de suas provas contra os quadrinhos. $\mathrm{O}$ motivo pelo qual usei a vasta quantidade de documentos que constituem a coleção de manuscritos de Fredric Wertham na Biblioteca do Congresso era dar sequência a minha pesquisa sobre como adultos serviam de gatekeepers da leitura de quadrinhos pelas crianças. Saí daquele trabalho documental uma pesquisadora mudada: as vozes das crianças - tanto as que Wertham examinou quanto as que lhe mandaram cartas - eram muitos fortes para eu ignorar.

$\mathrm{Na}$ fala de hoje, convido vocês a pensar comigo o que ganhamos na nossa compreensão da história dos quadrinhos, o discurso em torno do pânico moral coletivo, até no legado de Fredric Wertham, ao tirar a centralidade dessas pessoas com cargos de autoridade - as que criam os pânicos coletivos - e focar nas experiências dos jovens leitores. Espero que, em conjunto, reconheçamos o valor que há em ouvir as vozes de crianças de verdade, de jovens que tinham sua perspectiva, sua consciência e seu protagonismo em relação a quadrinhos e à leitura de quadrinhos. 
Vou começar com uma breve contextualização de Fredric Wertham e os quadrinhos dos Estados Unidos em meados do século 20. Depois, vou passar à discussão de alguns leitores em específico que Wertham estudou e dar alguns comentários de conclusão.

1 - Wertham e sua cruzada contra as revistas em quadrinhos

Fredric Wertham (Figura 1) foi um psiquiatra norte-americano nascido na Alemanha, que se especializou em psiquiatria forense. Ele começou a carreira nos Estados
Unidos nos anos 1920 na Clínica Psiquiátrica

Phipps do Hospital Johns Hopkins, um dos locais-chave para o avanço da psiquiatria moderna. Ele mudou-se para Nova York nos anos 1930, onde foi funcionário do Hospital Bellevue e outros estabelecimentos. Nos anos 1940, Wertham dedicava boa parte de seu ofício ao diagnóstico e tratamento de crianças que escolas, agências de assistência social, polícia e oficiais de justiça identificavam como delinquentes juvenis. Estes jovens - muitos dos quais eram afroamericanos - vinham de lares pobres nos bairros mais barra pesada da cidade.

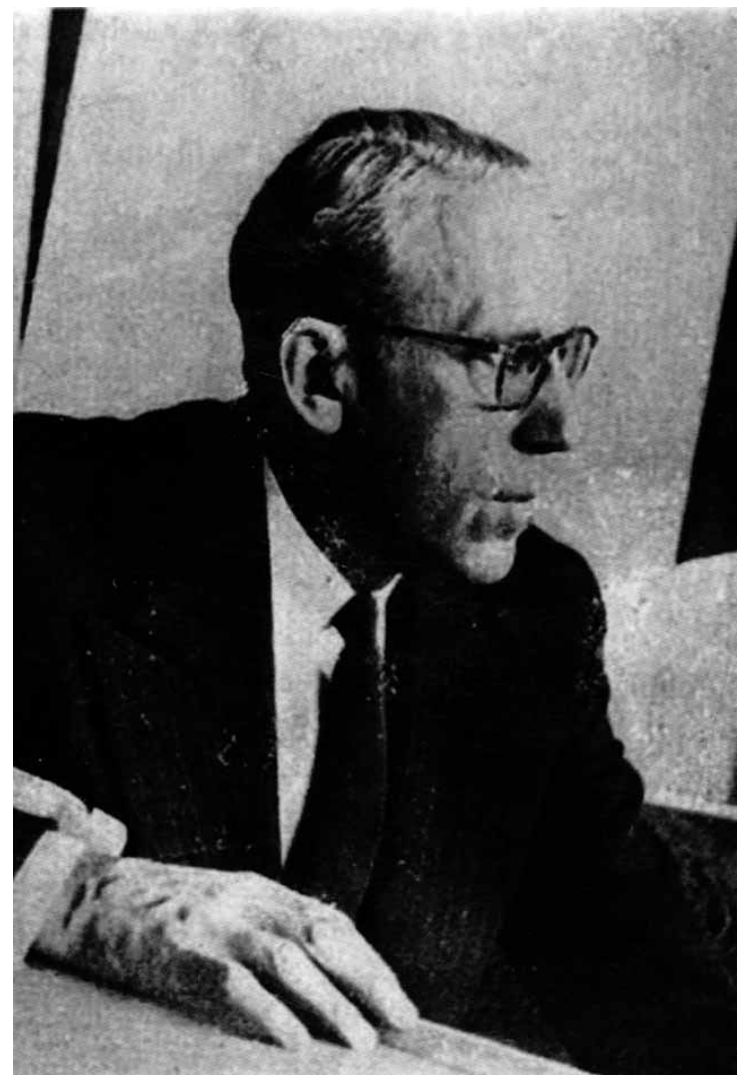

Figura 1 - Dr. Fredric Wertham Fonte: Disponível online: https:// art-bin.com/art/awertham.html
Afora a classificação de delinquência ou alguma questão comportamental como ansiedade ou pesadelos, o que quase todos os pequenos pacientes de Wertham tinham em comum - e o que ele mais buscou entender - era o passatempo de ler revistas em quadrinhos. $\mathrm{O}$ fato de seus pacientes lerem gibi foi, ao olhar de Wertham, tanto causa quanto sintoma dos distúrbios que ele buscava tratar.

Entre 1947 e 1954, Wertham palestrou e escreveu contra os quadrinhos com frequência, sempre baseando seus argumentos no que descrevia como investigações clínicas e científicas de jovens leitores de quadrinhos. A Sedução dos Inocentes, seu livro de 1954 (WERTHAM, 1954a) que teve trecho publicado na edição brasileira da Reader's Digest (WERTHAM, 1954b), argumentava que ler gibis do gênero policial, ou de crimes, prejudicava o desenvolvimento moral, social, físico e mental 
das crianças. Embora Wertham limitasse seu repúdio às revistas de crimes, ele alegava que quase todos os gibis publicados à época nos Estados Unidos - independentemente do gênero - eram gibis de crimes.

As revistas em quadrinhos foram o material impresso mais popular do século 20 , se não de todos os tempos. Só nos Estados Unidos, durante os anos de auge, todo mês os leitores compravam dezenas de milhões de gibis e trocavam, permutavam e dividiam gibis em números ainda maiores. As vendas subiram de aproximadamente 15 milhões de edições por mês em 1950 até quase 100 milhões de ediçóes por mês em 1953. Quase todas as crianças nos Estados Unidos, entre os 6 e os 12 anos, assim como muitos adolescentes, lia gibis em abundância. Adolescentes e adultos também liam quadrinhos, mas não na mesma proporção. Ainda assim, para sustentar o apelo dos quadrinhos com esses leitores de mais idade, que apresentavam gostos mais sofisticados, os editores incrementaram os gibis de superherói e bichinhos com outros gêneros, tais como românticos, terror, faroeste e ficção científica.

Ao longo dos anos 1940 e 1950, diversas autoridades individuais, educacionais, religiosas e governamentais manifestaram receios quanto aos efeitos que ler quadrinhos teria sobre as crianças. Embora Wertham não tenha sido a primeira nem a única voz anti-quadrinhos nos Estados Unidos, sua voz era a mais audível. Suas credenciais médicas e sua experiência como perito jurídico reforçavam sua autoridade.

Jovens de três clínicas compuseram as fontes primárias de suas provas em $A$ Seduçâa do Inocente. As Clínicas foram:

+ o Kings County Hospital, hospital público do Brooklyn, onde trabalhavam Wertham e a colega Dra. Hilde Mosse;

+ a Lafargue Clinic, no Harlem, multiclínica de preço acessível da qual Wertham foi co-fundador; e

+ o Quaker Emergence Readjustment

Center, serviço cuja principal meta era auxiliar homens e mulheres presos por atos de homossexualidade.

Os documentos de Wertham na Biblioteca do Congresso incluem anotações, relatórios de tribunais, testes psicológicos e diversos outros materiais sobre os pacientes cujas vidas serviram de fonte para o livro que ele escreveu.

Vou apresentar três das crianças pacientes.

\subsection{Ralph}

Ralph aparece em Sedução nas páginas 109-110. Na descrição de Wertham, a história de Ralph se destaca por ser preocupante. Ele escreveu que Ralph era um garoto de 11 anos que "colocou uma corda em volta" do pescoço de um menino mais novo, puxou forte e quase o estrangulou. Um mês depois, Ralph espancou o mesmo garoto no rosto. Wertham afirmava que Ralph "não sabia que não se bate em um garoto menor $\mathrm{e}$ mais novo. $\mathrm{O}$ que ele sabia era que esse tipo de coisa se faz em inumeráveis histórias em quadrinhos sobre assassinatos e assaltos" (WERTHAM, 1954, p. 110).

No livro, Wertham afirmou que não havia investigado o caso, mas que uma assistente social da Clínica Lafargue, do Harlem, havia. Na verdade, nem Wertham nem um dos clínicos conheceu a criança. Ralph foi visto por uma mulher que trabalhava no Exército da Salvação. Ela que comentou o caso com alguém na Clínica Lafargue.

O relato de Wertham quanto a casos de estrangulamento e espancamento até que fecham com o relatório escrito que ele deu, mas não ele conseguiu dar um contexto exato do incidente.

$\mathrm{Na}$ verdade Ralph tinha 13 anos, não 11. Era afro-americano, parte de uma família que, em termos econômicos, ficava nas margens entre pobreza e conforto. Ele tinha um problema cardíaco congênito e miopatia aguda. Não se sabe se a visão dele foi corrigida com óculos. De qualquer modo, é difícil imaginar que um menino negro, pobre, ruim da vista e com problema de saúde crônico, 
que morava num conjunto habitacional do governo, não tivesse sofrido bullying. Talvez ele só quisesse a experiência de tratar alguém do modo como ele fora tratado? Ou quem sabe, pelo menos em relação ao espancamento, ele estava fazendo retaliação por ser espancado como havia falado. Ele foi relutante em falar com a mulher do Exército da Salvação, então a maioria dos detalhes dos incidentes foram intermediados por sua mãe, que não fora testemunha de nenhum.

A mulher do Exército da Salvação perguntou à mãe de Ralph se ele lia gibis. A mãe "pareceu assustada e perguntou se faziam mal". Neste sentido, a mãe era igual a milhões de outros pais na época. A ubiquidade dos quadrinhos, tanto no geral quanto nas mãos de pequenos leitores, deixava muitos pais um tanto quanto cegos à sua existência: os gibis faziam parte da paisagem. Levantamentos indicam que vários pais compravam quadrinhos para os filhos, talvez a mãe de Ralph também.

Ela informou que ele lia Crime Does Not Pay (Figura 2) e Gang Busters (Figura 3), ambos títulos emblemáticos do gênero de crimes, que ganharam imensa popularidade na última metade dos anos 1940. O primeiro título estava no meio dos seus 13 anos de existência, enquanto o segundo - baseado num programa de rádio - era relativamente novo em 1948, quando ocorreu a visita de Ralph ao Exército da Salvação. O gênero de crimes era difundido nas mídias: foi a era dos programas de rádio com detetives, do cinema noir, dos livros policiais, das revistas pulp. Se Ralph não lesse gibis de crimes, há boas chances de que ele ia encontrar histórias parecidas em outras mídias.
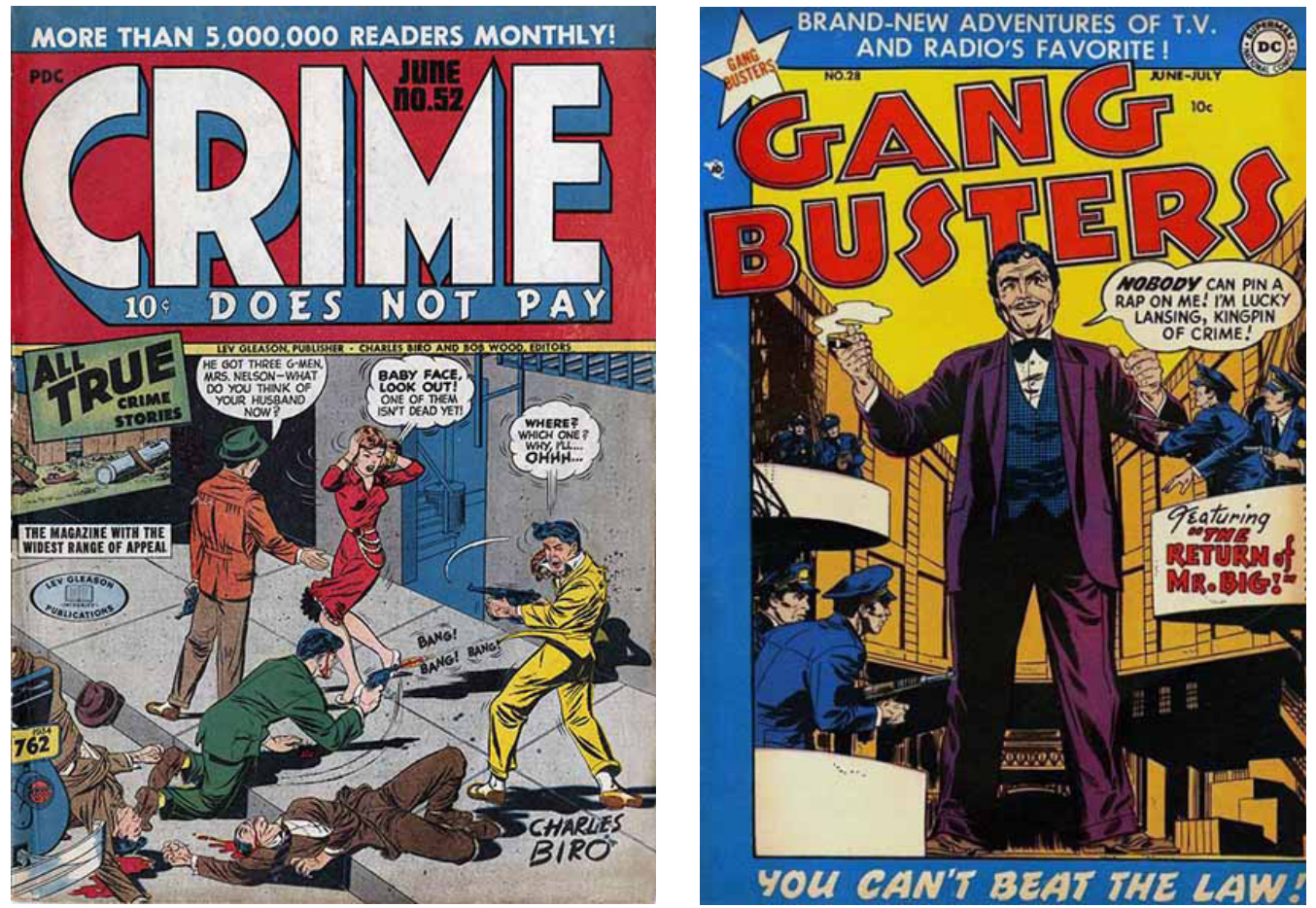

Figuras 2 e 3 - Titulos de revistas em quadrinhos citadas pelo jovem Ralph

Fonte: Disponíveis online: https://www.animationresources.org/pics/crime01-big.jpg e https://iwt.sfo2.cdn. digitaloceanspaces.com/cbr-covers/88265682f64ddb514c09888a3a37c511_xl.jpg

Quando foi questionado diretamente sobre quais quadrinhos lia, Ralph disse que gostava de Batman e Superman. Como Wertham fez em Sedução, Ralph falou nos assassinatos e assaltos que acontecem nestes gibis. Diferente de Wertham, Ralph enfatizava claramente que estes títulos de superherói eram focados nos personagens titulares capturarem assassinos e ladrões. 


\subsection{Vivian}

Nossa segunda criança é Vivian, que aparece em Sedução nas páginas 40 e 41. Wertham a descreveu como "uma garota meiga e simpática de doze anos" que estava em tratamento "porque roubou dinheiro de um inquilino" (1954, p. 40). Ele informa um caso que ela contou, sobre o roubo de um bracelete; ela lera em um quadrinho romântico. Wertham a chamou de "perita em quadrinhos românticos" e comentou que ela gostava de devanear (1954, p. 41).

O relato de Wertham foi incompleto e, em grande parte, impreciso.

Vivian era uma menina afroamericana de 13 anos, que fora levada à clínica pela madrasta. Segundo as anotações clínicas, seu último boletim era "excelente", segundo a mãe, e Vivian tocava piano "maravilhosamente". Ela pode ter roubado um ou dois dólares de um dos inquilinos na casa de família de sua mãe.

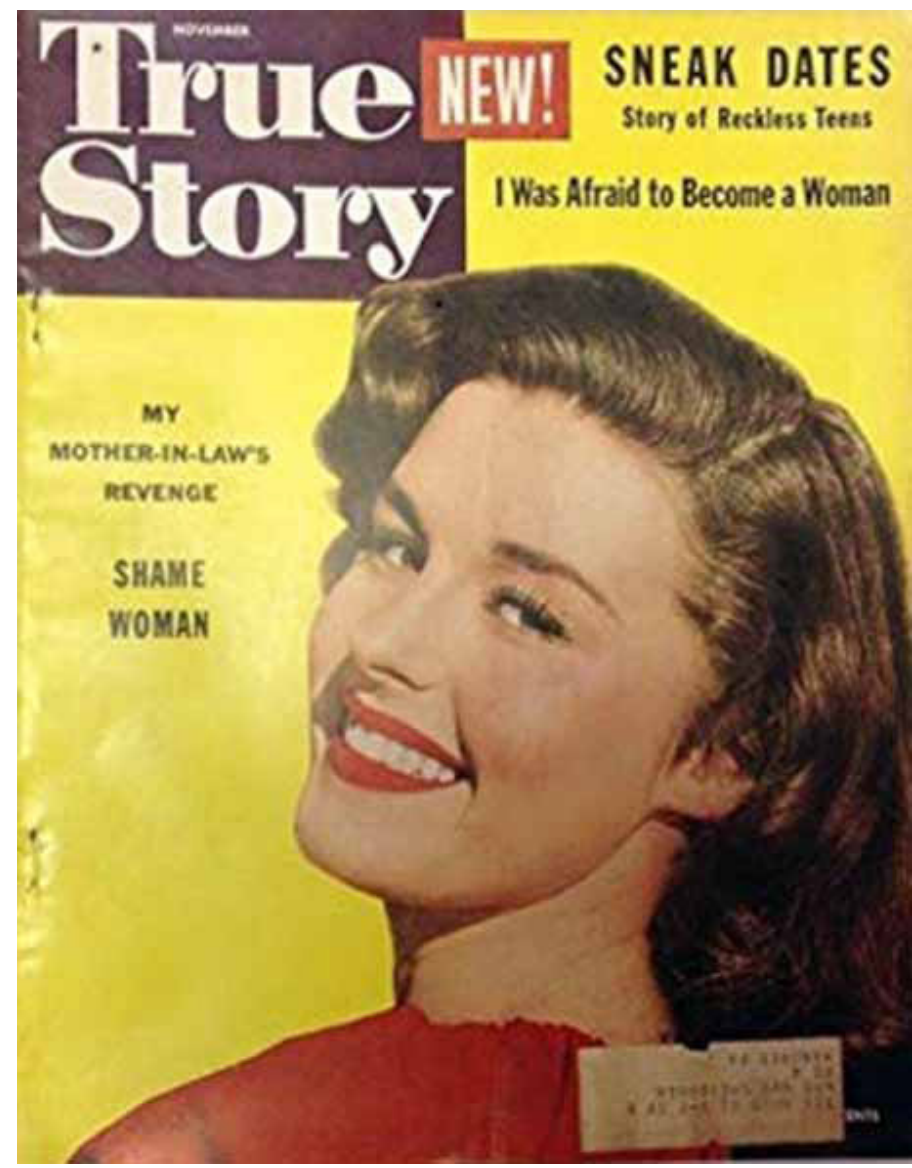

Figuras 4 - True Story, revista citada pela jovem Vivian (que não era de quadrinhos) Fonte: Disponível online: https://images-na.ssl-images-amazon.com/images/ I/71fMzEWgU6L._AC_SX342_.jpg
Ela também pode ter roubado um anel do professor de piano. A mãe de Vivian informou que a menina era mentirosa.

A madrasta de Vivian, que batera nela pelo menos em uma ocasião, queria internar a menina. Nas anotações clínicas, informa-se que ela disse: "Mãe diz que querem internar ela. 'Eu acho que ela não tem como sair disso. Todo mundo me diz pra dar uma chance. A gente tem dado chance e não acontece nada. Eu quero que ela vá pra um lar católico. Ela não é católica, mas eu deixaria que fosse pra que fosse internada."

Não fica claro, a partir das anotaçóes, se Wertham chegou a conhecer Vivian na uma ou duas consultas que ela fez à clínica em fevereiro de 1951.

Mas e os quadrinhos? Vivian lia mesmo. Ela disse que, quando tinha, ela lia quadrinhos românticos. "Compro uma vez que outra, mas principalmente troco", ela informou. Os títulos que ela cita incluíam Superman e Crime Does Not Pay. Na verdade, a história que ela contou sobre o bracelete roubado estava em Crime Does Not Pay, não num quadrinho romântico como Wertham disse.

Vivian citou outras publicações, como a True Story (Figura 4), que era uma revista feminina de contos que começou a se voltar para interesses das adolescentes. É importante ressaltar que não eram revistas em quadrinhos, mas Wertham não fez distinção. Ela disse que lia uma coisa chamada Romance. Havia dezenas de gibis com romance no título. Vivian se referiu a um específico ou só ao gênero de quadrinhos que fazia mais sucesso na época?

No total, Vivian não se identificou como uma grande leitora de quadrinhos, embora ela e a madrasta tenham afirmado que ela lia desde pequena. Segundo vários levantamentos realizados nos anos $1940 \mathrm{e}$ 1950, os treze anos eram quando a leitura de revistas em quadrinhos de muitas crianças começava a diminuir, então não é inesperado que a leitura de gibis por parte 
de Vivian tenha virado algo em grande parte oportunista. Trocar gibis era comum entre crianças e, como parece que Vivian não tinha muito dinheiro, faz sentido que as trocas fossem o principal meio para ela adquirir.

Vivian observou que sua madrasta não queria que ela lesse quadrinhos porque "eles interferem nos meus deveres no colégio". Ler gibi estava tornando-se problema menor, contudo, porque, como sua madrasta informou, Vivian não lia "tantos quadrinhos porque agora tinha a televisão".

\subsection{Richard}

Richard é a última criança que quero thes apresentar hoje. Wertham conta parte da história dele na página 158 de Sedução. Chamando-o de Gerald, Wertham o descreve como um menino de 11 anos que fez vários roubos em lojas, fazendo parte de uma quadrilha de garotos de mais idade. "Uma noite, depois de uma peripécia destas, dois policiais os seguiram. Gerald tinha uma arma de chumbinho, virou-se e atirou num dos policiais. Foi acusado de assalto à mão armada" (1954, p. 158). Gerald/Richard declarou que se sentia apto para ir a tribunal porque havia lido a respeito em gibis, nos quais Wertham também dizia que ele aprendeu o desprezo pela lei.

Richard é um caso interessante porque ele foi tratado diversas vezes em um período de três anos - de 1950 a 1952 - mas não por Wertham. Richard foi paciente de Hilde Mosse, psiquiatra e colega de Wertham. Parte do motivo pelo qual Richard fora conduzido a tratamento foram pequenos roubos com frequência. Os registros também afirmam que ele mentia, o que rende suspeita sobre os causos em que ele conta que beijava meninas, que passou por iniciação em gangues e que roubava sacos do correio de vagões de trem.

E essa história de ter atirado num policial com uma arma de chumbinho?
Richard não era o culpado. Ele não tinha uma dessas armas, mas falou que gostaria de ter. Quem atirou foi um garoto chamado Paul. Richard, que tinha 12 anos na época, estava entre oito meninos naquele grupo naquela noite. Ele foi preso no dia seguinte, junto com todos os outros, no colégio. Não há registro nas anotações clínicas sobre o resultado da audiência. Richard contou à Dra. Mosse que ele sentia culpa principalmente por deixar a mãe insatisfeita.

No caso de Richard, os quadrinhos parecem menos inspiração para más escolhas na vida e mais uma maneira de lidar com o mundo. Ele afirmou que se inspirava a fazer coisas e a desenhar lendo quadrinhos. Ele informou que vendia gibis sem capa por um centavo e outros por entre três e oito centavos de dólar, dependendo de como estivesse a capa. Numa das entrevistas ele dizia ter 200 quadrinhos, mas em algum momento seu pai jogou fora uma pilha de "gibis de morte" porque era contra.

As anedotas de Richard com quadrinhos abrangem uma pequena parte da sua pasta. Embora Wertham tenha levado os leitores a pensar em Richard como leitor de gibis de crimes, na verdade ele gostava mais dos com o Capitão Marvel. Dos quatro títulos que ele citou, dois - Captain Marvel Adventures (Figura 5) e Master Comics (Figura 6) - eram séries da Fawcett que traziam esse famoso personagem. Ele se atraía pelo personagem porque "Eles sempre brigam com os bandidos. Eu gosto quando fazem assim. Eles são gente comum e se transformam em gente forte."

É essa citação de Richard - o fascínio que ele tem por gente comum que ganha superpoderes - que se destaca pra mim. Por quê? As anotaçóes clínicas dizem que, quando ele tinha 8 anos, meninos mais velhos o levaram a um mato, obrigaram-no a abaixar as calças e "mandaram fazer coisas". Outras anotações dizem que meninos urinaram no seu rosto. 
Os dois incidentes podem ser o mesmo; não fica claro nas anotações. Em várias vezes em que ele discute como meninos mais velhos aterrorizavam os mais novos, ameaçando com facas, dizendo que iam bater. Talvez, como conjecturou Wertham, ler quadrinhos tenha levado aos roubos e à prisão de Richard, mas acredito ainda mais que ler quadrinhos lhe deu sensação de esperança.
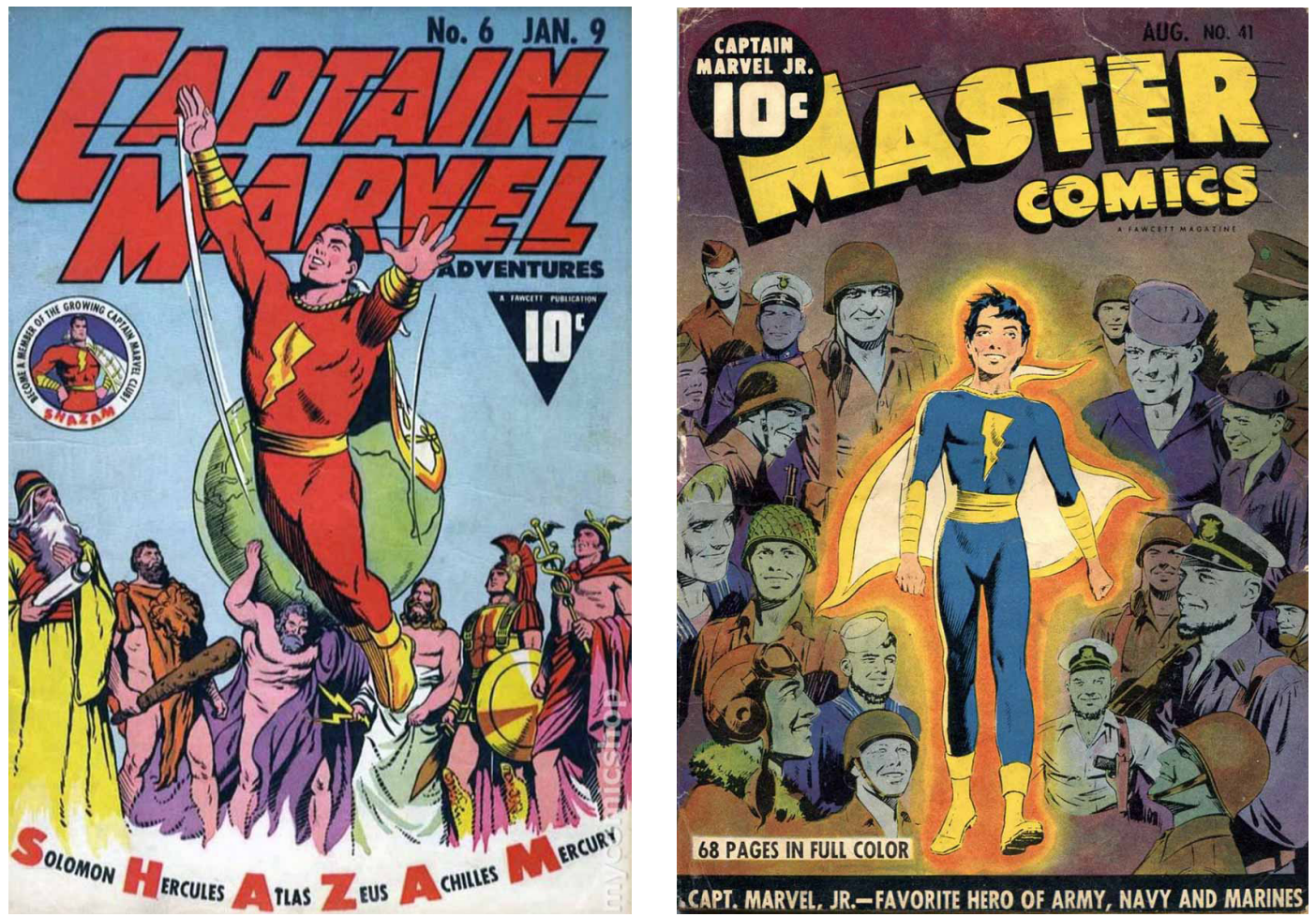

Figuras 5 e 6 - Títulos de revistas em quadrinhos citados pelo jovem Richard. Fonte: Disponíveis online: https://d1466nnw0ex81e.cloudfront.net/n_iv/600/778811.jpg e https://box01.comicbookplus.com/viewer/3f/3f28f28a1295e3528cc9c2fa49636ec1/0.jpg

2 - As revistas em quadrinhos a partir da visão dos fãs

Como eu disse, minhas primeiras pesquisas sobre quadrinhos enfocaram gatekeepers que tentam controlar como crianças liam quadrinhos. Ao me deparar com as vozes de crianças de verdade, como Ralph, Vivian e Richard, fui incentivada a mudar o foco do meu trabalho. Nos sete anos desde que publiquei as provas das deturpações de Wertham, eu me esforço para recuperar as vozes dos leitores de quadrinhos americanos jovens, dos anos 1930 aos 1950, o ápice de popularidade dos quadrinhos. Encontrei dezenas de levantamentos esquecidos, cartas que fãs enviaram a autores, assim como cartas que eles enviaram a Wertham e a senadores dos Estados Unidos. Comecei a documentar atividades participativas, tais como criação de fanzines, criação de quadrinhos para jornais de colégio e o uso dos quadrinhos de base para atividades de caridade ou sociais. Entrevistei adultos que eram leitores de quadrinhos quando crianças, naquelas décadas.

Esse trabalho se mostrou muito gratificante. As perspectivas que eu recolhi me levaram a começar a escrever um livro, cujo título provisório é Comics and Youth: How a Mass Medium Transformed a Generation (Quadrinhos e Juventude: Como uma Mídia de Massa Transformou uma Geração). 


\section{Conclusão}

Temos muito a aprender sobre quadrinhos, mídia de massa, pânicos morais coletivos e culturas participativas se nos dedicarmos a procurar e ouvir leitores, tanto jovens quanto velhos. Há desafios abundantes, sobretudo ao estudar leitores históricos e leitores infantis para quem a evidência existe na forma mais efêmera.

Espero que vocês tenham se inspirado ao saber mais sobre alguns leitores centrais às mentiras de Fredric Wertham. Sei que há histórias de muitos leitores no Brasil que ainda precisam ser contadas.

\section{Referências}

GILBERT, James. A cycle of outrage: America's reaction to the juvenile delinquent in the 1950s. New York: Oxford University Press, 1988.

TILLEY, Carol L. Seducing the innocent: Fredric Wertham and the falsifications that helped condemn comics. Information \& Culture: a journal of history, Austin, University of Texas, v. 47, n. 4, p.383-413, 2012.

WERTHAM, Fredric. (A) The seduction of the innocent. New York: Kennikat Press, 1954.

WERTHAM, Fredric. (B) Roteiro para a delinquência. Seleções do Reader's Digest, p. 113-125, Set. 1954. 